\title{
Effectiveness of brace treatment for adolescent idiopathic scoliosis
}

\author{
Toru Maruyama*, Yosuke Kobayashi, Makoto Miura, Yusuke Nakao \\ From The 10th Meeting of the International Research Society of Spinal Deformities (IRSSD 2014 Sapporo) \\ Sapporo, Japan. 29 June - 2 July 2014
}

\section{Objectives}

Effectiveness of brace treatment for adolescent idiopathic scoliosis (AIS) was demonstrated by the BrAIST study in 2013. Objectives of this study were to analyze outcomes of our brace treatment to confirm the effectiveness of brace treatment for AIS and to clarify the factors affecting the results of the treatment.

\section{Materials and methods}

According to the Scoliosis Research Society (SRS) AIS brace studies standardization criteria, patients with age 10 years or older, Risser 0 to II, less than 1 year postmenarche, curve magnitude 25 to 40 degrees before brace treatment and who received no prior treatment were included in the study. At skeletal maturity, the rate of the patients whose curve was stabilized, exceeded 45 degrees, and who were recommended or underwent surgery were investigated. Additionally, initial correction rate by the brace was calculated comparing pre-treatment Cobb angle and first in-brace Cobb angle. Factors that affected the results of the treatment were investigated.

\section{Results}

A total of 33 patients (27 females and 6 males) could be followed-up until their skeletal maturity and included in the analysis. An average age was 11.9 years, average Cobb angle was 30.8 degrees, and Risser sign was 0 in 13 patients, I in 5 patients, and II in 15 patients before treatment. There were 13 thoracic curves, 14 thoracolumbar or lumbar curves, and 6 double curves. Initial correction rate by the brace was $53.8 \%$ for the total curves. In terms of curve pattern, $34.4 \%$ for thoracic curve, $73.9 \%$ for thoracolumbar or lumbar curve, and $48.8 \%$ for double curve.

Saitama Medical Center, Saitama Medical University, Japan
After an average follow-up period of 33 months, 8 patients improved in more than 6 degrees, change of 17 patients were within 6 degrees, and 8 progressed in more than 6 degrees. Therefore, totally, 76\% (25/33) of the curves were stabilized by the treatment. Four curves (12\%) exceeded 45 degrees and one patient (3\%) underwent surgery. Our results were better than the reported natural history. Factors that affected the results were hump degree $(\mathrm{p}=0.0204)$ before treatment and initial correction rate by the brace $(\mathrm{p}=0.0048)$.

\section{Conclusions}

$76 \%$ of the curve with AIS could be stabilized by brace treatment. The effectiveness of brace treatment for AIS was confirmed by our results. Factors that affected the results of the treatment were hump degrees before treatment and initial correction rate by the brace.

Published: 19 January 2015

doi:10.1186/1748-7161-10-S1-062

Cite this article as: Maruyama et al.: Effectiveness of brace treatment for adolescent idiopathic scoliosis. Scoliosis 2015 10(Suppl 1):O62.

Submit your next manuscript to BioMed Central and take full advantage of:

- Convenient online submission

- Thorough peer review

- No space constraints or color figure charges

- Immediate publication on acceptance

- Inclusion in PubMed, CAS, Scopus and Google Scholar

- Research which is freely available for redistribution 